\title{
Kegel Exercises, Biofeedback, Electrostimulation, and Peripheral Neuromodulation Improve Clinical Symptoms of Fecal Incontinence and Affect Specific Physiological Targets: An Randomized Controlled Trial
}

\author{
Lluís Mundet, ${ }^{1,2 *}$ Laia Rofes, $^{1,2,3}$ Omar Ortega, ${ }^{1,2}$ Christopher Cabib, ${ }^{1}$ and Pere Clavé ${ }^{1,2}$ \\ ${ }^{\prime}$ Gastrointestinal Physiology Laboratory, Department of Surgery, Hospital de Mataró, Universitat Autònoma de Barcelona, Mataró, Spain; \\ ${ }^{2}$ Centro de Investigación Biomédica en Red de enfermedades hepáticas y digestivas (CIBERehd), Instituto de Salud Carlos III, Barcelona, Spain; \\ and ${ }^{3}$ Neos Surgery, Parc Tecnológic del Vallès, Cerdanyola del Vallès, Barcelona, Spain (Current address)
}

\section{Background/Aims}

Fecal incontinence (FI) is a prevalent condition among community-dwelling women, and has a major impact on quality of life (QoL). Research on treatments commonly used in clinical practice-Kegel exercises, biofeedback, electrostimulation, and transcutaneous neuromodulation - give discordant results and some lack methodological rigor, making scientific evidence weak. The aim is to assess the clinical efficacy of these 4 treatments on community-dwelling women with $\mathrm{Fl}$ and their impact on severity, QoL and anorectal physiology.

\section{Methods}

A randomized controlled trial was conducted on 150 females with $\mathrm{Fl}$ assessed with anorectal manometry and endoanal ultrasonography, and pudendal nerve terminal motor latency, anal/rectal sensory-evoked-potentials, clinical severity, and QoL were determined. Patients were randomly assigned to one of the following groups: Kegel (control), biofeedback + Kegel, electrostimulation + Kegel, and neuromodulation + Kegel, treated for 3 months and re-evaluated, then followed up after 6 months.

\section{Results}

Mean age was $61.09 \pm 12.17$. Severity of $\mathrm{Fl}$ and QoL was significantly improved in a similar way after all treatments. The effect on physiology was treatment-specific: Kegel and electrostimulation + Kegel, increased resting pressure $(P<0.05)$. Squeeze pressures strongly augmented with biofeedback + Kegel, electrostimulation + Kegel and neuromodulation + Kegel $(P<0.01)$. Endurance of squeeze increased in biofeedback + Kegel and electrostimulation + Kegel $(P<0.01)$. Rectal perception threshold was reduced in the biofeedback + Kegel, electrostimulation + Kegel, and neuromodulation + Kegel $(P<0.05)$; anal sensory-evoked-potentials latency shortened in patients with electrostimulation + Kegel $(P<0.05)$.

\section{Conclusions}

The treatments for $\mathrm{Fl}$ assessed have a strong and similar efficacy on severity and QoL but affect specific pathophysiological mechanisms. This therapeutic specificity can help to develop more efficient multimodal algorithm treatments for Fl based on pathophysiological phenotypes.

(J Neurogastroenterol Motil 2021;27:108-118)

Key Words

Biofeedback; Electric stimulation; Fecal incontinence; Pelvic floor disorders; Transcutaneous electric nerve stimulation 
Received: January 29, 2020 Revised: April 16, 2020 Accepted: July 3, 2020

(.) This is an Open Access article distributed under the terms of the Creative Commons Attribution Non-Commercial License (http://creativecommons. org/licenses/by-nc/4.0) which permits unrestricted non-commercial use, distribution, and reproduction in any medium, provided the original work is properly cited.

*Correspondence: Lluís Mundet, PhD, RN

Gastrointestinal Physiology Laboratory, Hospital de Mataró, Carretera de Cirera, 230, Mataró 08304, Barcelona, Spain Tel: +34-937-417-700, E-mail: Iluismundetp@gmail.com

\section{Introduction}

Fecal incontinence $(\mathrm{FI})$ is a common condition affecting up to $15 \%$ of community-dwellers. ${ }^{1}$ It is socially disabling, and although clinical severity correlates with impaired $\mathrm{QoL},{ }^{2}$ it has recently been illustrated that the most important independent factor impacting QoL is gender. ${ }^{3}$

FI occurs when one or more structures and functions involved in continence are disrupted, and when the remaining mechanisms are unable to compensate. Anal sphincter weakness-due to direct muscular damage or neuropathic injury, rectal sensitivity impairment, and loose fecal consistency ${ }^{4}$ are some of the most common factors involved, and these frequently overlap. In a recent study we confirmed that, besides mechanical external anal sphincter (EAS) and internal anal sphincter dysfunctions due mainly to obstetric factors, previously unexplored impaired and delayed conduction through sensory anorectal pathways and secondary reduced cortical activation in response to electrical stimulation are very prevalent pathophysiological factors associated with FI in women. ${ }^{5}$ In effect the proportion of patients with FI with an afferent/sensory dysfunction was much higher than in the case of those with peripheral pudendal motor conduction impairments, which is a well-known pathophysiological mechanism for $\mathrm{FI}^{5}$

FI treatment remains a clinical challenge. Surgical procedures have quite unpredictable long-term results in the long-term, and therefore conservative rehabilitation treatments are recommended as a first line treatment. These include Kegel exercises $(\mathrm{K})$, biofeedback (BF), endoanal or endovaginal electrostimulation (ES), or tibial nerve neuromodulation (NM) through percutaneous or transcutaneous electrodes (tNM). Although their use is common, there is a lack of evidence about their clinical efficacy, and the physiological targets they affect are not fully understood, often resulting in an empirical choice of treatment. ${ }^{6,7}$ Pelvic floor exercises or $\mathrm{K}$, although a commonly recommended treatment for FI patients, have demonstrated their utility as a coadjutant treatment only, and not as a stand-alone one. ${ }^{8}$ Regarding BF therapy, this is considered a first-line treatment. ${ }^{9}$ However, studies which have tried to assess its efficacy do not show consistent results, ${ }^{10}$ and at least 1 study showed no advantage of BF over K. ${ }^{11}$ Regarding ES, significant differences vs controls have not been found, but a recent study ${ }^{12}$ claimed that a combination of $\mathrm{BF}+\mathrm{ES}$ was more effective than monotherapy; overall however, there is not enough evidence to judge the efficacy of ES or to select the right patients for this treatment. ${ }^{13}$ Regarding peripheral NM, 2 systematic reviews concluded that NM can be an effective therapy for $\mathrm{FI},{ }^{14}$ but a recent multi-center study showed discouraging results. ${ }^{15}$ Overall there is a high degree of variability in study design and results, and furthermore, there is considerable heterogeneity in the translation of these results into clinical practice.

Additionally, the effect of these treatments on anorectal physiology is even less clearly understood. $\mathrm{K}$ and BF focus on the mechanical action of the pelvic floor muscles, but a classic study ${ }^{16}$ found no changes in mean resting pressure (MRP) or squeeze pressure (SP) in patients treated with $\mathrm{BF}$; according to others, $\mathrm{BF}$ can indeed improve $\mathrm{MRP}^{17} \mathrm{SP}^{18-20}$ as well as endurance of SP (ESP), rectoanal coordination, and rectal perception. ${ }^{18}$ With regard to ES, it has been suggested that it has an effect not only on slow and fast-twitch fibers of the muscle, but also on the very same neural pathways. ${ }^{13,21}$ Regarding NM, the action mechanism is little known, but it has been strongly suggested that it affects both motor and sensorial functions. ${ }^{22}$ Overall, the efficacy of the treatments is probably highly dependent on the pathophysiology underlying FI, hence the discordant results, so it is key on one hand to understand the pathophysiology, and on the other, to understand the action mechanisms of the treatments.

The main aim is to compare the clinical efficacy of 4 rehabilitation techniques ( $\mathrm{K}, \mathrm{BF}, \mathrm{ES}$, and $\mathrm{tNM}$ ) in reducing the severity of FI symptoms in community-dwelling women and to explore their influence on anorectal physiology at a biomechanical and, secondarily at a neurophysiological level. We hypothesize that BF, ES, and tNM are superior treatments for FI compared to K, and that they affect specific aspects of impaired anorectal physiology.

\section{Materials and Methods}

Patients attending the gastrointestinal physiology unit from February 2013 to March 2017 with a history of more than 6 months of FI symptoms were consecutively screened. Patients with 
mild FI (Cleveland $<4$ ), under 18 years of age, and those unable to follow the treatment properly were excluded. The study was conducted according to the principles laid down in the Declaration of Helsinki, and obtained Ethics Committee approval (code: 67/12). Written informed consent was obtained from the participants.

This is a randomized controlled trial (RCT) with a parallel design (TrialsGov: NCT03394794) with 4 treatment arms: K (base treatment, control group), $\mathrm{BF}+\mathrm{K}, \mathrm{ES}+\mathrm{K}$, and $\mathrm{tNM}+\mathrm{K}$, with a calculated sample of 45 patients in each group. Sample size was calculated to assess changes in severity (primary endpoint) of an active treatment compared to control $(\mathrm{K})$ with Granmo software version 7.12 (IMIM, Barcelona, Spain) assuming an alpha risk of 0.05 and a beta risk of 0.20 , a SD of 3.2 (for Cleveland score) and a minimum expected difference of 2 . A simple randomization method was performed using QuickCalcs (GraphPad Software, San Diego, USA). The study had 2 stages: an initial 3-month stage with the patients receiving the assigned treatment to assess its efficacy (effect on clinical severity and $\mathrm{QoL}$ ) and its effect on physiology, and a second 3-month stage, continuing only with $\mathrm{K}$ as a maintenance treatment to evaluate the persistence of the effects of the treatment (clinical severity and QoL) (Fig. 1).

Primary endpoint was the change before and after treatments in the severity score (Cleveland score); secondary outcomes were the effects on the anorectal physiology and neurophysiology.

\section{Diagnostic and Therapeutic Methods}

Demographics and complete medical histories, comorbidities, risk factors, and medications were collected on Visit 1.

\section{Clinical severity and quality of life assessment}

FI clinical severity was assessed using the Cleveland Incontinence Score, ${ }^{23}$ fecal consistency with the Bristol Stool Chart, ${ }^{24}$ and severity of urinary incontinence (UI) with the International Con- sultation on Incontinence Questionnaire (ICIQ) score. ${ }^{25}$ FI-related QoL and general health-related QoL were assessed using Fecal Incontinence Quality of Life (FIQL) score ${ }^{2}$ and EQ-5D, ${ }^{26}$ respectively.

\section{Anal sphincter structure}

A Hitachi ultrasound (endoanal ultrasonography [EUS]) with an endoanal $10-\mathrm{MHz}$ transducer (Hitachi Medical Corporation, Tokyo, Japan) was used to assess internal/external sphincters and puborectalis anatomic integrity. ${ }^{5}$

\section{Anorectal manometry}

Anorectal function was studied using conventional anorectal manometry to measure MRP, SP, and ESP. To assess ESP, 4 common pressure profiles were identified when patients held SP for 10 seconds. ${ }^{5}$ Cough reflex, sensory thresholds, and rectoanal inhibitory reflex (RAIR) were also assessed. Data was acquired using a Polygraph ID (Medtronic, Minneapolis, MN, USA). All these procedures are fully described previously, ${ }^{5}$ and are those recommended by the Spanish Motility Group.

\section{Pudendal nerve terminal motor latency}

In a randomized subsample of 10 patients from each therapeutic group, the terminal efferent pathway was also studied with pudendal nerve terminal motor latency (PNTML) (Neuromodule, MMS, Enschede, the Netherlands) on both sides. ${ }^{5}$ Metrics recorded and analyzed were latency of the compound muscle action potential (CMAP), amplitude, duration, and area under the curve of the CMAP. ${ }^{27}$

\section{Event-related long-latency anorectal sensory evoked potentials and sensory thresholds}

In a second randomized subsample of 10 patients from each

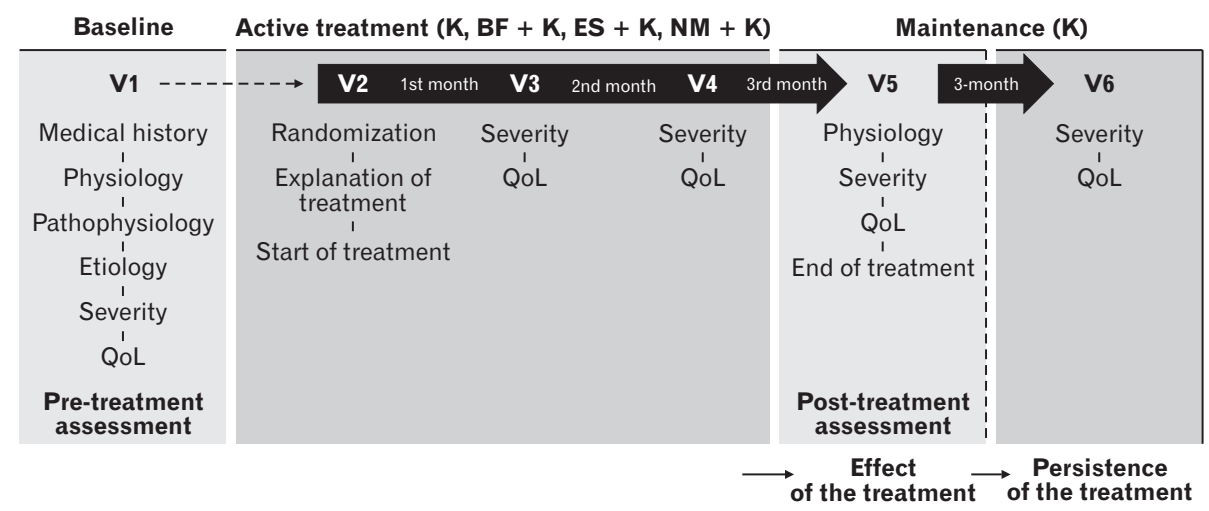

Figure 1. Study design. Baseline, active treatment period, and follow-up period. K, Kegel exercises; BF, biofeedback; ES, electrostimulation; tNM, transcutaneousneuromodulation; ARM, anorectal manometry; EUS, endoanal ultrasonography; PNTML, pudendal nerve terminal motor latency; SEP, sensory evoked potentials. 
therapeutic group, sensory evoked potential (SEP) to anal (ASEP) and rectal (RSEP) electrical stimulation were studied. Anal and rectal mucosa were stimulated using a customized probe. Electroencephalographic signals were analyzed and SEP obtained in $\mathrm{Cz}$ (at the vertex scalp) for being the cortical site of maximal representation after anorectal stimulation. Latencies of the peaks p1, n1, p2, and $\mathrm{n} 2$ were analyzed, as well as amplitudes of p1-n1, n1-p2, and p2n2.

\section{Treatments}

Group 1. K (control): Patients were given oral and written instructions on how to perform $\mathrm{K}$ at home. They had to exercise for 10 minutes 3 times a day for a 3 -month period. The exercises included maximal fast and sustained squeeze exercises (Supplementary Fig. 1).

Group 2. $\mathrm{BF}+\mathrm{K}$ : In addition to $\mathrm{K}$, patients received six 45-minute BF sessions administered by a specialist nurse (Supplementary Fig. 2). BF training was focused on the strengthening of the EAS muscle ${ }^{28}$ and the coordination of EAS contraction with rectal distention. Sensory training was not performed. Patients laid down looking at a monitor that mirrored the tracings of a manometric BF unit. The type of exercises was the same as $\mathrm{K}$.

Group 3. ES + K: In addition to K, patients were instructed on the home use of an electric stimulation unit (Elpha 3000 Conti; Danmeter A/S, Odense, Denmark) with a "Periform +" endovaginal probe (Neen Healthcare, Dereham, UK). The stimulator was to be used for 30 minutes a day, 5 days a week, set at a frequency of $35 \mathrm{~Hz}$, pulse-width of 300 microseconds with cycles of 0.5 -second ramp-up, 5 seconds on, 0.5-second ramp-down, and 5 seconds off. Patients were told to increase intensity until reaching their tolerance threshold. $^{29}$

Group 4. tNM + K: In addition to $K$, patients were instructed on the home use of a neuromodulation unit (Elpha 3000 Conti; Danmeter A/S) provided with self-adhesive transcutaneous electrodes (one above tibial malleolus and $2 \mathrm{~cm}$ from the medial line, and a second one below the malleolus), and used for 30 minutes a day, 5 days a week; at $20 \mathrm{~Hz}$ with a pulse width of 200 microseconds. Stimulation was increased until a motor response of the first toe was observed, this being the therapeutic intensity for the patient. $^{30}$

\section{Statistical Methods}

Continuous variables were expressed as means (SD) and compared with $t$ tests or non-parametric tests when appropriate. ANOVA was used to compare more than 2 groups. Categorical variables were compared with chi-square/Fisher's exact tests. Normal range limits were calculated from our own laboratory data gathered in healthy volunteers. ${ }^{5}$ To assess the differences in the cortical localization of the SEP before-after treatments, the sLORETA software (KEY Foundation for Brain-Mind Research, Zurich, Switzerland) was used. ${ }^{5,31} P$-values $<0.05$ were considered statistically significant.

Patients were divided into responders and non-responders to the treatments, the first being those where severity changed from Cleveland $\geq 9$ to $<9$ post treatment (those with Cleveland $<9$ prior to treatment were not taken into account). The reason for this

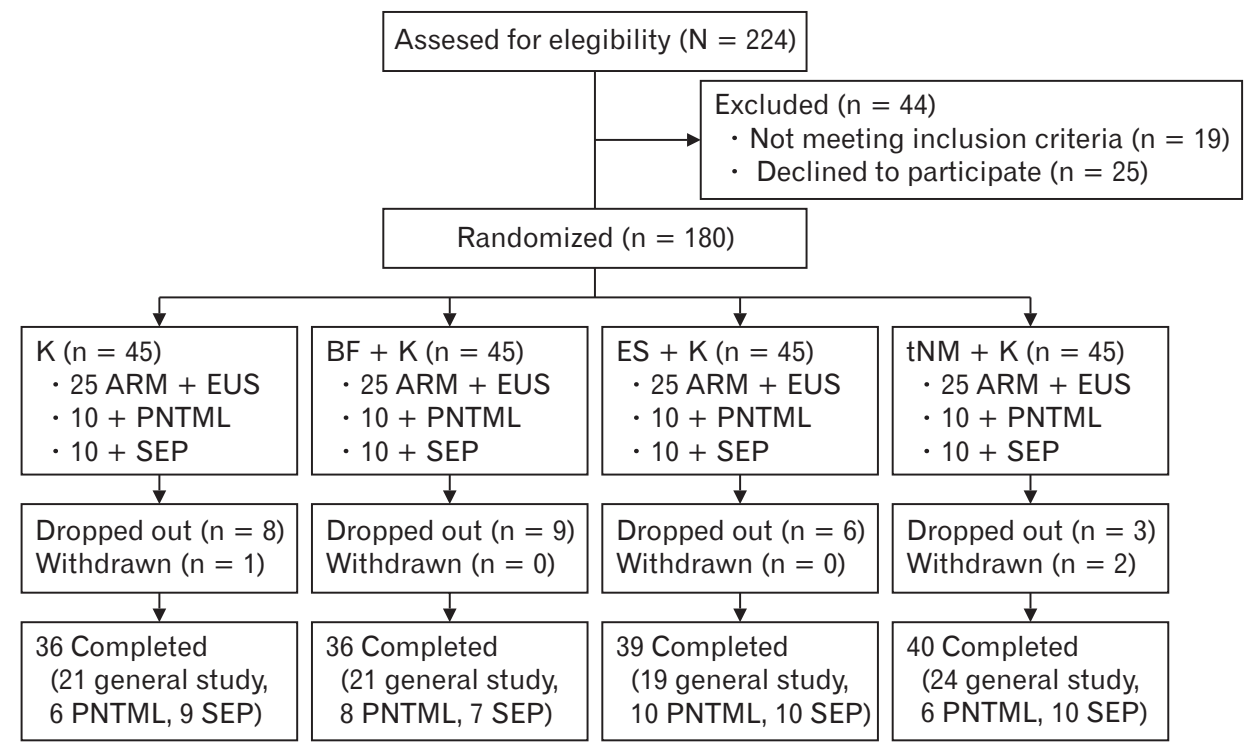

Figure 2. Flow diagram of patients' recruitment and drop outs, with final participants in each arm. K, Kegel exercises; BF, biofeedback; ES, electrostimulation; tNM, transcutaneous neuromodulation; ARM, anorectal manometry; EUS, endoanal ultrasonography; PNTML, pudendal nerve terminal motor latency; SEP, sensory evoked potentials. 
cut-off point for the assessment of the response to treatment derives from previous studies that demonstrated that in patients with Cleveland $<9$ the impact on QoL was very low, compared with patients with Cleveland $\geq 99^{2,32}$ To facilitate comparison with results from other studies, we also analyzed the results by considering as responders those patients with a reduction of $\geq 50 \%$ in the clinical severity of FI (Table).

\section{Results}

One hundred and eighty patients were included in the study and randomly assigned to one of the treatment groups (Fig. 2). The mean age was $61.09 \pm 12.17$ years. Complettion of the study was 36 patients in the $\mathrm{K}, 36$ in the $\mathrm{BF}+\mathrm{K}, 39$ in the $\mathrm{ES}+\mathrm{K}$, and 40 in the $\mathrm{tNM}+\mathrm{K}$ group. Drop out was due to discomfort, an inability to self-administer the treatments, or the fact that patients simply did not return despite being sent reminders.

\section{Baseline Parameters}

The full clinical characteristics and pathophysiology of FI in these patients have been previously published (Supplementary Tables 1 and 2). ${ }^{5}$ Most patients had a history of obstetric risk factors, and pathophysiology was mainly associated with mechanical sphincter dysfunctions, most showing urge FI (83.1\%; from these, $44.7 \%$ also with passive FI), mainly due to EAS weakness because of muscular sphincteric damage and, to a lesser degree, to sphincter denervation. Passive FI alone was present in 17\%. On the sensorial side, more than a quarter had rectal sensitivity impairments (mainly hyposensitivity), and moreover, impaired conduction through afferent anorectal pathways was also very prevalent. Clinical severity was moderate to severe (Cleveland $11.55 \pm 3.80$ ).

\section{Effect of the Treatments on Clinical Severity and Quality of Life}

Cleveland score showed a significant reduction in clinical severity of $31.68 \%$ in the $\mathrm{K}$ group, and more than $40.00 \%$ in the $\mathrm{BF}+$ $\mathrm{K}(41.70 \%), \mathrm{ES}+\mathrm{K}(46.20 \%)$, and tNM + K (47.50\%) groups, although there was no statistical difference between them. Data is shown in Table. The FIQL score showed that QoL improved significantly in all 4 dimensions (life style, coping, embarrassment, and depression) for patients from all treatment groups. There were no statistical differences between the groups. Regarding general healthrelated QoL, EQ5D showed no differences in any of the score categories after any particular treatment. Transforming qualitative data from the questionnaire into a summary index $(0-1)$, the health

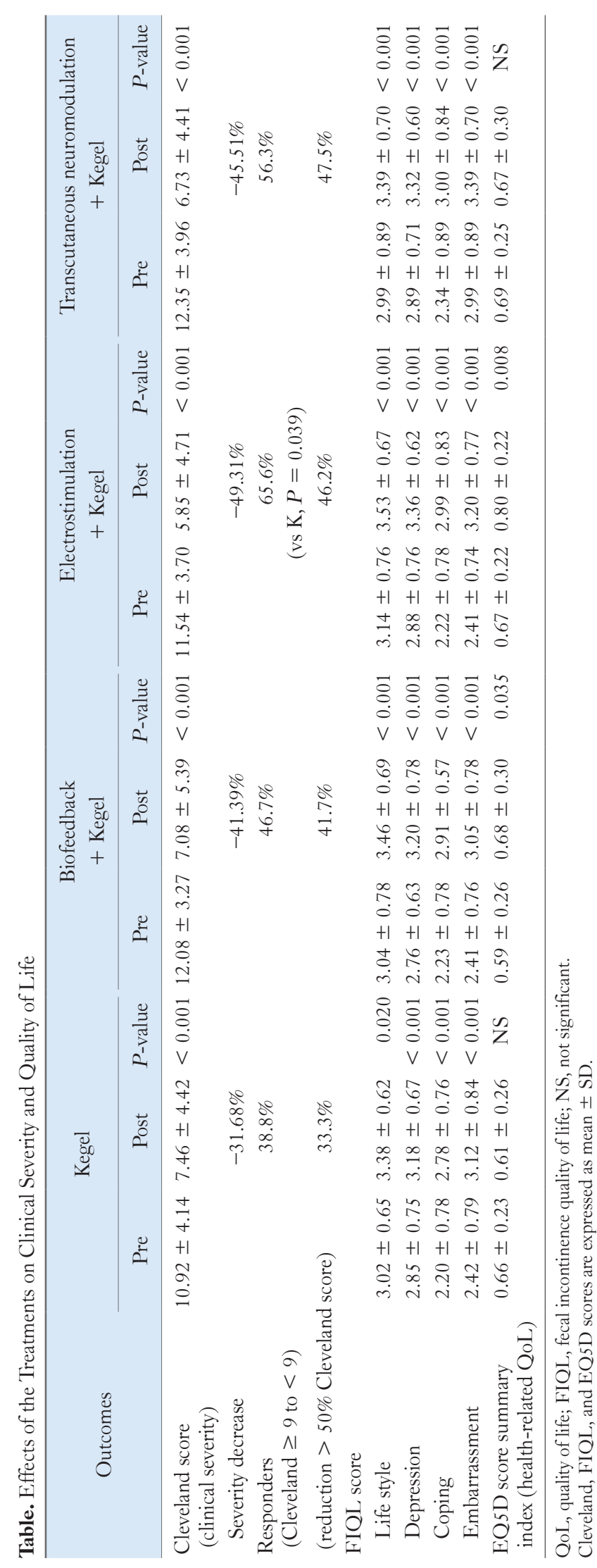


status of patients in the $\mathrm{BF}+\mathrm{K}$ and $\mathrm{ES}+\mathrm{K}$ groups improved significantly (Table).

\section{Factors Associated With Response to the Treatments}

According to our definition of responders as those achieving a Cleveland score $<9$, the response rate was $38.50 \%, 46.70 \%$, $65.60 \%$, and $56.30 \%$ for, $\mathrm{K}, \mathrm{BF}+\mathrm{K}, \mathrm{ES}+\mathrm{K}$, and $\mathrm{NM}+\mathrm{K}$, respectively (difference between $\mathrm{K}$ and $\mathrm{ES}$ is significant, $P=0.039$ ). We also analyzed factors associated with a negative response to a treatment: rectal hypersensitivity (OR, 5.08; 95\% CI, 1.03-25.10), passive FI (OR, 4.8; 95\% CI, 1.32-17.44), and feces with Bristol $>5$ (OR, 3.52; 95\% CI, 1.05-11.80). The multivariate analysis confirmed passive $\mathrm{FI}$ as an independent factor associated to a negative response to any treatment $(\mathrm{OR}, 11.37$; $95 \% \mathrm{CI}, 2.02-63.97)$. Being younger was a positive response factor $(\mathrm{OR}, 0.88 ; 95 \% \mathrm{CI}$, 0.79-0.97).

\section{Persistence of Treatment Effects}

In the 3-month follow-up period after the treatments in which all patients continued to perform Kegel exercises only, the observed positive effect of treatments on clinical severity was sustained in all

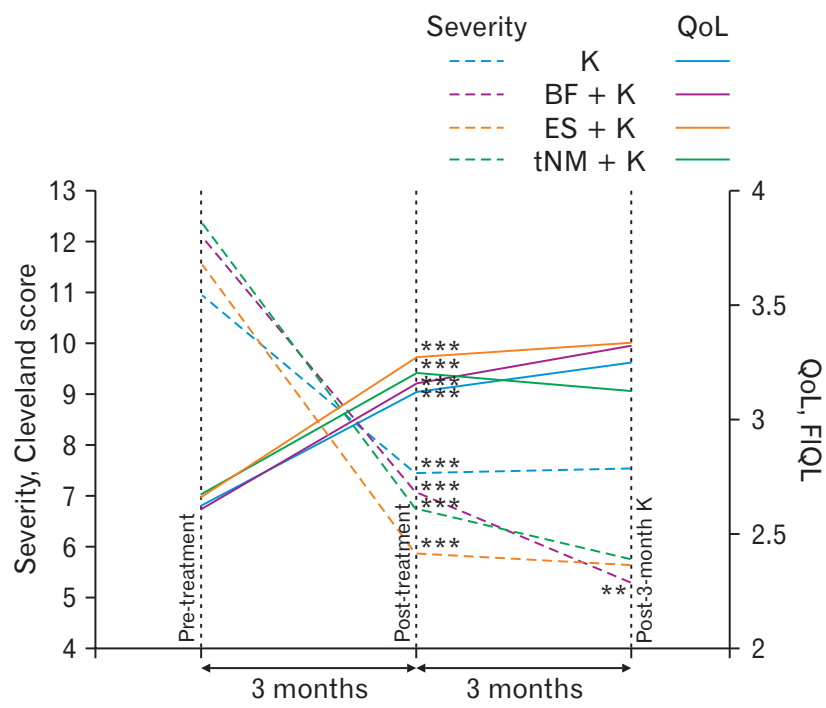

Figure 3. Effect of all 4 treatments on clinical severity (Cleveland score) and on quality of life (QoL) (Fecal Incontinence Quality of Life [FIQL] score). Differences between V1 and V5 (active treatment) were all significant $(* * * P<0.001)$. Differences between the end of the treatment (V5) and the end of the final 3-month followup (V6) were significant for the Cleveland score in the biofeedback $(\mathrm{BF})+$ Kegel exercises $(\mathrm{K})$ group $\left({ }^{* *} P<0.01\right)$. Note that, in order to avoid cluttering, FIQL values are means of the 4 subscales values. ES, electrostimulation; tNM, transcutaneous neuromodulation. cases; $\mathrm{BF}+\mathrm{K}$ patients further improved their symptoms. Regarding QoL, post-treatment effects were also steadily maintained during the entire follow-up phase (Fig. 3).

\section{Effect of the Treatments on Anorectal Physiology}

\section{Biomechanical effects}

Sphincter function. The effect of treatments on MRP was minimal but statistically significant after $\mathrm{K}$ and $\mathrm{ES}+\mathrm{K}$ treatments. In contrast, SP significantly increased to a much higher degree following all treatments except for K (Fig. 4 and Supplementary Table 3). The percentage of patients with effective ESP profiles after treatment also increased significantly in those treated with $\mathrm{BF}+\mathrm{K}$ and ES + K (Fig. 5 and Supplementary Table 3).

Responses to rectal distention. Patients treated with $\mathrm{tNM}+\mathrm{K}$ required a lower volume of distension post-treatment to elicit RAIR $(19.41 \pm 6.48 \mathrm{~mL}-16.67 \pm 5.95 \mathrm{~mL}$, beforeafter treatment, respectively; $P<0.05$ ). Regarding sensitivity in response to rectal distention, the threshold for the first perception in patients in the $\mathrm{BF}+\mathrm{K}$ and $\mathrm{ES}+\mathrm{K}$ groups was significantly reduced after treatment $(P<0.05)$ (differences in the $\mathrm{tNM}+\mathrm{K}$ group near statistical significance). Other data regarding sensory changes are shown in Supplementary Table 4.

\section{Neurophysiological effects}

Motor pathways. Baseline PNTML was homogeneous between groups. No statistically significant difference was found in

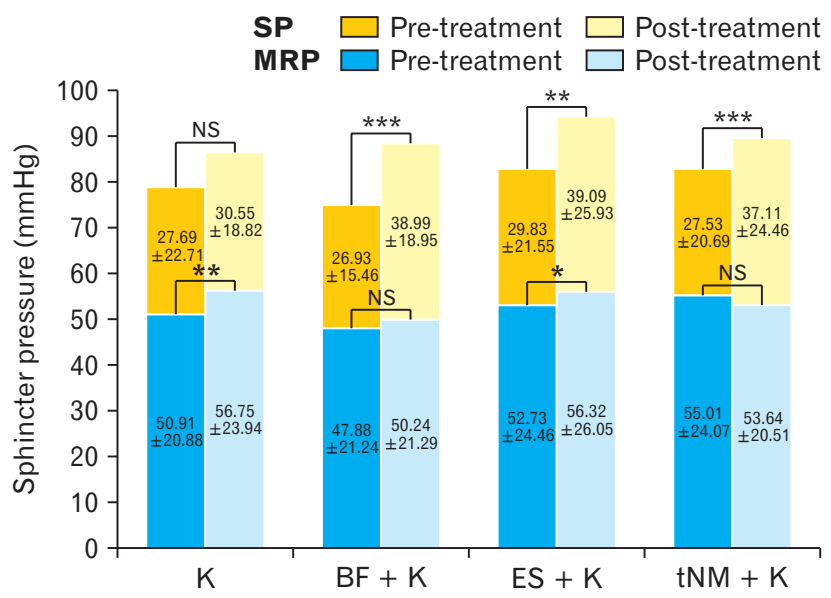

Figure 4. Comparison of mean resting pressure (MRP) and squeeze pressure $(\mathrm{SP})$ in $\mathrm{mmHg}$ before and after the treatments $\left({ }^{\star} P<0.05\right.$, ${ }^{* *} P<0.01$, and ${ }^{* *} P<0.001$, respectively). K, Kegel exercises; BF, biofeedback; ES, electrostimulation; tNM, transcutaneous neuromodulation; NS, not significant. 
Patients with effective pressure profiles pre-treatment Patients with effective pressure profiles post-treatment

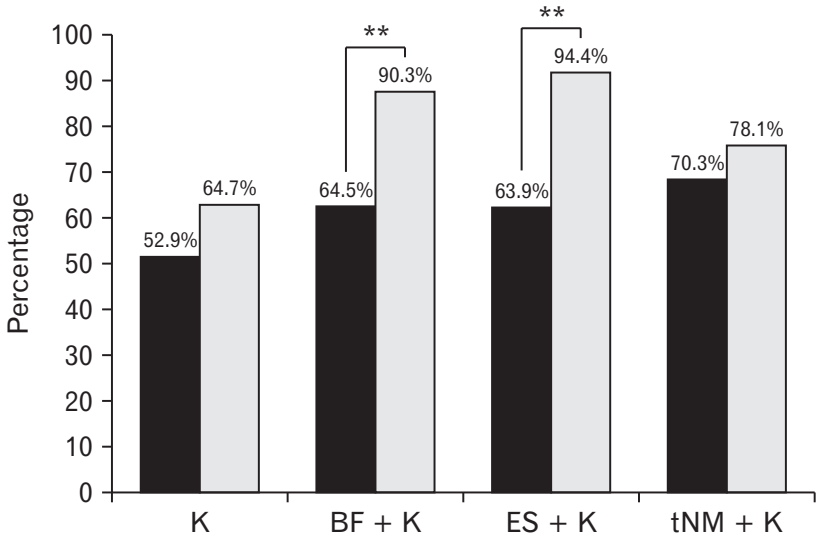

Figure 5. Percentage of patients with effective pressure profiles (adequate endurance of squeeze pressure [ESP]) before and after treatments. ESP was assessed according to the pressure profile when holding voluntary contraction for 10 seconds $(* * P<0.01)$. K, Kegel exercises; BF, biofeedback; ES, electrostimulation; tNM, transcutaneous neuromodulation. terms of latency, amplitude, duration, and area under the curve of CMAP after any of the treatments (Supplementary Table 3).

Sensorial pathways. For the ASEP, we found significantly shorter latencies of peak p1 after ES + K, (81.14 \pm 12.21 milliseconds_-70.86 \pm 11.65 milliseconds, before-after treatment, respectively; $P=0.046$ ). No changes were found in RSEP latency after treatment in any group.

\section{Cortical sensory evoked potential source localization}

We compared the anal representation in brain cortex activation before and after treatments. We found increased activation of the cingulate gyrus area (corresponding to Broadmann area [BA] 32) in patients treated with $\mathrm{ES}+\mathrm{K}$ for $\mathrm{p} 1$, and a decrease in the superior temporal gyrus (corresponding to BA22) for n2. Also, after treatment with $\mathrm{BF}+\mathrm{K}$, a decrease in the activation in the cingulate area (BA31) was observed for $\mathrm{n} 1$ (all differences statistically significant) (Fig. 6). Regarding the areas of rectal representation, no differences were found in any of the treatments.

\section{Other Effects of the Treatments}

There was a statistically significant decrease in the ICIQ score

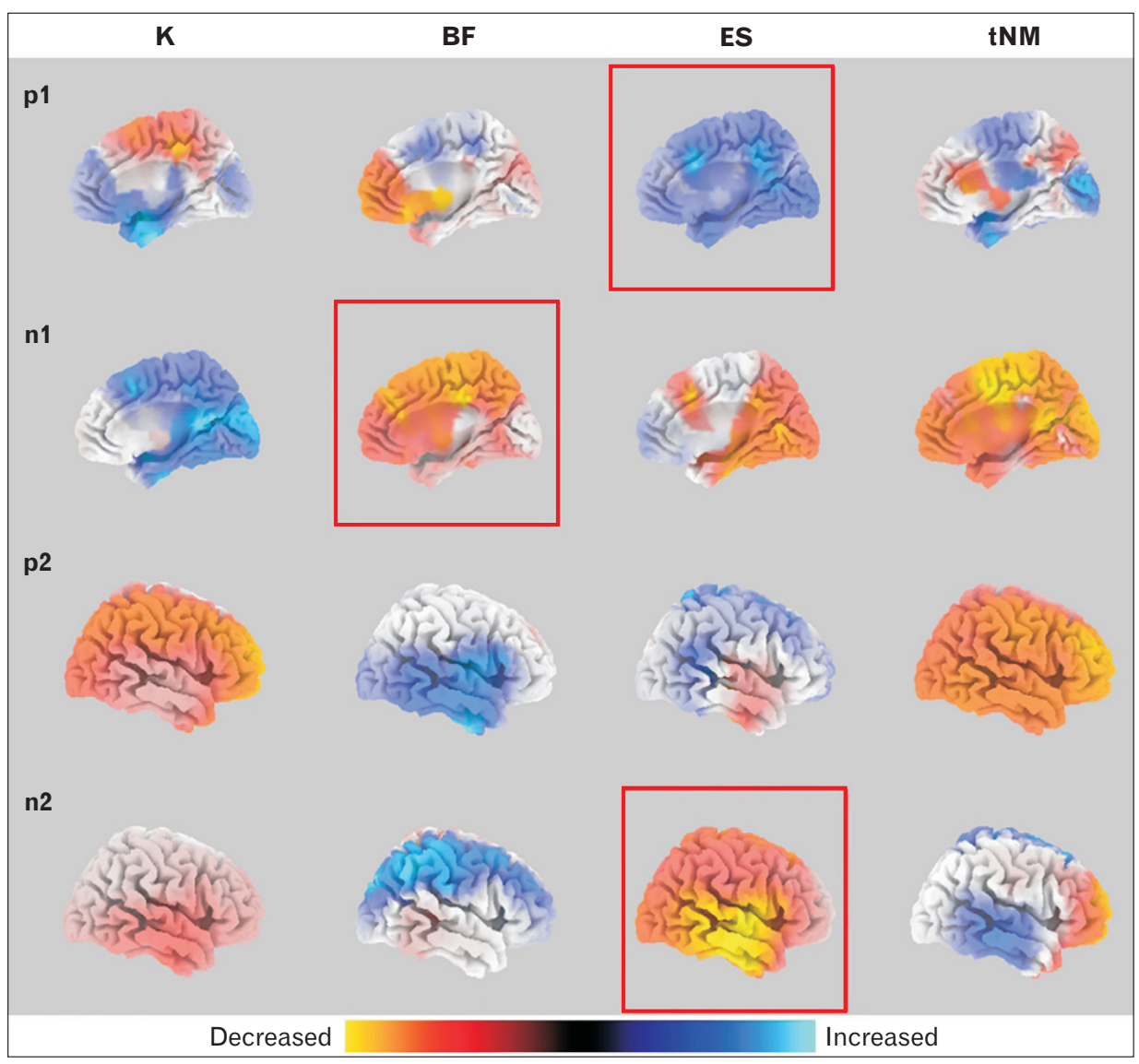

Figure 6. Mean group differences in sLORETA source activity for $\mathrm{p} 1$, $\mathrm{n} 1, \mathrm{p} 2$, and n2 (grand average) after anal stimulation (anal sensory evoked potentials $[\mathrm{ASEP}]$ ) comparing before and after treatment activation. Colored voxels represent areas of significant difference (blue, increase; red, decrease). Red squared projections indicate where differences before and after treatments were statistically significant. K, Kegel exercises; BF, biofeedback; ES, electrostimulation; tNM, transcutaneous neuromodulation. 
at 3 months post-treatment in patients with UI treated with $\mathrm{K}, \mathrm{ES}$ $+\mathrm{K}$ and $\mathrm{tNM}+\mathrm{K}$ (Supplementary Table 5). These results were maintained at the 3 -month follow-up stage.

Fecal consistency was evaluated before, during, and after the treatment period. We observed that the percentage of patients in the $\mathrm{tNM}+\mathrm{K}$ group with very loose stools (Bristol 6 and 7) diminished after the 3-month active treatment, that is, fecal consistency changed to Bristol $\leq 5$ (32.7\% pre-treatment and $7.5 \%$ posttreatment; $P=0.016$ ).

\section{Discussion}

The rehabilitation treatments assessed in this study for FI in community-dwelling women $(\mathrm{K}, \mathrm{BF}+\mathrm{K}, \mathrm{ES}+\mathrm{K}$, and $\mathrm{tNM}+$ $\mathrm{K})$ showed strong and similar therapeutic efficacy in terms of clinical severity and QoL. However, they affect specific and distinct pathophysiological mechanisms. Previous studies have tried to assess the therapeutic efficacy of individual treatments compared to control groups, $8,10,11,13,15,19,20,33$ with varying results, but to our knowledge no study has compared the efficacy of these 4 therapies and their effects on so many different aspects of anorectal physiology.

\section{Effect on Clinical Severity and Quality of Life}

All the treatments for FI strongly improved clinical severity, especially in the $\mathrm{ES}+\mathrm{K}$ and $\mathrm{tNM}+\mathrm{K}$ groups compared to control group $(\mathrm{K})$, achieving a decrease of almost $50 \%$ in the Cleveland score. This data is similar to that obtained by Healy et $\mathrm{al}^{34}$ using $\mathrm{ES}$, and Boyle et $\mathrm{al}^{35}$ using NM (percutaneous); there are few studies of $\mathrm{tNM}$, and one ${ }^{30}$ showed almost no improvement. Regarding $\mathrm{BF}$, the improvement in our patients was more pronounced than in most other studies. ${ }^{8,11,36}$ QoL improved for all patients regardless of the treatment applied; FI-related QoL is associated not only with the severity of FI, but also with previous mood disorders, age and gender, $^{3}$ which implies that in the management of FI consideration of the patient's individual characteristics must be included. The 3-month follow-up post-treatment using only $\mathrm{K}$ in all groups shows that both the improvement in clinical severity and the recovery of $\mathrm{QoL}$ achieved during each treatment were maintained. So, although $\mathrm{K}$ proved to be less effective during the treatment period, it would appear reasonable to recommend it as a maintenance therapy during follow up.

\section{Effects on Motor Responses}

In patients treated with $\mathrm{K}$ and $\mathrm{ES}+\mathrm{K}, \mathrm{MRP}$ increased minimally, probably insufficient to counterbalance FI symptoms associated with EAI impairment. The small increments in MRP observed may be attributable to an improvement in EAS tonic contraction and their modest contribution to the anal canal resting pressure. In contrast, the effect of BF, ES, and tNM on the voluntary squeeze (striated muscle) was of much greater magnitude allowing patients to delay defecation for longer, and minimize urgeFI symptoms. K exercises only did not cause the expected changes in EAS contractility, probably because patients may not have been fully aware of which muscle group they were exercising, hence the importance of monitoring with BF. The ineffective ESP profiles prior to treatment changed to a much better sustained pressure in a significant percentage of patients treated with $\mathrm{BF}$ and with $\mathrm{ES}$, suggesting that both treatments are able to increase slow-twitch fiber contractility.

The improvements in SP observed in patients treated using tNM cannot be attributed to a direct effect on sphincters, but to an effect outside the anorectal region ${ }^{37}$; patients treated with tNM showed a tendency to shorter PNTML, suggesting that a higher proportion of muscle fibers in the EAS is activated after a potential re-innervation. On the other hand, through the stimulation of afferent pathways, ${ }^{38}$ tNM may be able to induce changes that occur in CNS and, in turn, improve motor control of the pelvic muscles. To sum up, BF and ES would be useful techniques to help patients with EAS insufficiency and intact efferent pathways, while tNM seems a reasonable treatment for those with pudendal motor nerve impairment, although more research needs to be carried out.

\section{Effect on Sensory Responses}

Sensorial perception in the rectum and anal canal is decisive in preserving continence. BF and ES improved the first rectal perception threshold, the most objective sensorial landmark measured with anorectal manometry. ${ }^{39}$ While BF promotes immediate sensorial learning generated by the motor task, direct activation of sensory axons by $\mathrm{ES}^{21,34}$ probably induces more complex central learning mechanisms leading to proprioception. Patients treated with tNM also showed improvement in the first perception (near to statistical significance), the results being in line with those obtained in previous studies with $\mathrm{SNS},{ }^{40}$ changes that must also be linked to neuroplasticity phenomena.

From the neurophysiological perspective, after treatment with ES, patients exhibited a shortening of the latency of p1 of the ASEP; this finding suggests an influence of ES on afferent pathways, probably resulting in better integration of sensory inputs and control of the pelvic floor muscles. 


\section{Other Effects of the Treatments}

In the $\mathrm{tNM}$ group the percentage of patients with loose stools (Bristol $>5$ ) diminished very significantly post-treatment, suggesting that tNM can modulate colonic activity ${ }^{41}$ and that the change in fecal consistency could explain in part the improvement in many patients with FI. Likewise, is also remarkable that patients after treatment with $\mathrm{tNM}$ required smaller volumes of distension to initiate RAIR suggesting an influence on the mechanisms that regulate rectal compliance.

As expected, patients also suffering from UI and treated with $\mathrm{K}, \mathrm{ES}+\mathrm{K}$, and $\mathrm{tNM}+\mathrm{K}$ experienced a significant improvement in the severity of the clinical symptoms of UI. It is noteworthy that patients treated solely with $\mathrm{K}$ improved UI symptoms but not FI, which reinforces the argument that some treated with this therapy for FI probably focus on the contractile activity on urogenital muscles other than the EAS and the puborectalis.

\section{Responders}

In order to identify which patients responded to a particular treatment, the rule of a decrease in symptoms of more than $50 \%$ is commonly used. This criterion, in our opinion, implies the acceptance of decreases in symptoms after a treatment that may be no more than marginal. Changes from grave clinical severity before treatment (Cleveland $\geq 9$ ) to mild or moderate severity (Cleveland $<9)$ as a positive response seems to us more reasonable as the impact on QoL in one range or another is highly significant. ${ }^{2}$ In these terms, the percentage of responders was higher for $\mathrm{ES}+\mathrm{K}(65.5 \%)$ and $\mathrm{tNM}+\mathrm{K}(56.3 \%)$ than for the other 2 treatments.

Regardless of the treatment assigned, only a small percentage of patients with rectal hypersensitivity (20.0\%), loose stools $(26.7 \%)$, or passive FI (29.4\%) responded to treatment. The latter was an independent factor associated with a negative response to the treatment. Rectal hypersensitivity and passive FI are challenging conditions that require further research, as no current treatment appears to really mitigate the symptoms. On the other hand, the influence of fecal consistency in response of the treatment is critical, ${ }^{4}$ being essential to treat diarrhea before attempting any rehabilitation.

Our study has some limitations. One is the absence of a sham control groups. Kegel was intended to act as control but it does not omit the therapeutic element of the research, and bias remain possible because of the unblinded design. Another is the limited sample of patients in each group, which has prevented the clarification of certain aspects, especially those regarding the study of neurophysiology. In RSEP recording, it was difficult to ensure intrarectal probe positioning — although contact with mucosa was confirmed - in order to ensure the repeatability of the procedures. In addition, we could not include the FI episodes as a primary outcome, because data was not strictly reliable.

To conclude, our research highlights the strong therapeutic effect of the therapies studied in those patients that complete the protocol treatment, and their distinct pathophysiological targets. This will help us to define a multimodal algorithm for treatment with distinct pathophysiological phenotypes of patients with FI that need a specific treatment and approach, and should begin with the treatment of diarrhea, if present. Future studies should assess the clinical therapeutic efficacy of multimodal treatment algorithms to further improve patients' symptoms, and help them to regain $\mathrm{QoL}$ and return to their normal way of life.

\section{Supplementary Materials}

Note: To access the supplementary tables and figures mentioned in this article, visit the online version of Journal of Neurogastroenterology and Motility at http://www.jnmjournal.org/, and at https://doi.org/10.5056/jnm20013.

Acknowledgements: All authors thank Dr Mateu Serra and Elisabet Palomera for their statistical support; Jane Perkins for assistance with English; Daniel Alvarez for his help with some of the images; and Jordi Roig from DPM for his support on Elpha stimulators.

Financial support: Part of this research was funded through 2 PERIS grants from the Catalonian Health Department (SLT002/16/00214 and SLT008/18/00168). CIBERehd is funded by Instituto de Salud Carlos III, Barcelona, Spain.

\section{Conflicts of interest: None.}

Author contributions: Study conception and design: Lluís Mundet, Pere Clavé, and Laia Rofes; data collection and analysis: Lluís Mundet, Omar Ortega, Christopher Cabib and Laia Rofes; writing of the manuscript: Lluís Mundet, Christopher Cabib, and Pere Clavé; and final approval: Pere Clavé. All authors approved the final version of the article, including authorship list.

\section{References}

1. Ng KS, Sivakumaran Y, Nassar N, Gladman MA. Fecal incontinence: community prevalence and associated factors--a systematic review. Dis Colon Rectum 2015;58:1194-1209. 
2. Minguez M, Garrigues V, Soria MJ, Andreu M, Mearin F, Clave P. Adaptation to Spanish language and validation of the fecal incontinence quality of life scale. Dis Colon Rectum 2006;49:490-499.

3. Mundet L, Ribas Y, Arco S, Clavé P. Quality of life differences in female and male patients with fecal incontinence. J Neurogastroenterol Motil 2016;22:94-101.

4. Bharucha AE, Zinsmeister AR, Schleck CD, Melton LJ 3rd. Bowel disturbances are the most important risk factors for late onset fecal incontinence: a population-based case-control study in women. Gastroenterology 2010;139:1559-1566.

5. Mundet L, Cabib C, Ortega O, et al. Defective conduction of anorectal afferents is a very prevalent pathophysiological factor associated to fecal incontinence in women. J Neurogastroenterol Motil 2019;25:423-435.

6. Lal N, Simillis C, Slesser A, et al. A systematic review of the literature reporting on randomised controlled trials comparing treatments for faecal incontinence in adults. Acta Chir Belg 2019;119:1-15.

7. Meyer I, Richter HE. Evidence-based update on treatments of fecal incontinence in women. Obstet Gynecol Clin North Am 2016;43:93-119.

8. Solomon MJ, Pager CK, Rex J, Roberts R, Manning J. Randomized, controlled trial of biofeedback with anal manometry, transanal ultrasound, or pelvic floor retraining with digital guidance alone in the treatment of mild to moderate fecal incontinence. Dis Colon Rectum 2003;46:703710.

9. Lee BH, Kim N, Kang SB, et al. The long-term clinical efficacy of biofeedback therapy for patients with constipation or fecal incontinence. J Neurogastroenterol Motil 2010;16:177-185.

10. Norton C, Cody JD. Biofeedback and/or sphincter exercises for the treatment of faecal incontinence in adults. Cochrane Database Syst Rev 2012:CD002111.

11. Norton C, Chelvanayagam S, Wilson-Barnett J, Redfern S, Kamm MA. Randomized controlled trial of biofeedback for fecal incontinence. Gastroenterology 2003;125:1320-1329.

12. Vonthein R, Heimerl T, Schwandner T, Ziegler A. Electrical stimulation and biofeedback for the treatment of fecal incontinence: a systematic review. Int J Colorectal Dis 2013;28:1567-1577.

13. Hosker G, Cody JD, Norton CC. Electrical stimulation for faecal incontinence in adults. Cochrane Database Syst Rev 2007:CD001310.

14. Horrocks EJ, Thin N, Thaha MA, Taylor SJ, Norton C, Knowles CH. Systematic review of tibial nerve stimulation to treat faecal incontinence. Br J Surg 2014;101:457-468.

15. Horrocks EJ, Bremner SA, Stevens N, et al. Double-blind randomised controlled trial of percutaneous tibial nerve stimulation versus sham electrical stimulation in the treatment of faecal incontinence: CONtrol of Faecal Incontinence using Distal NeuromodulaTion (the CONFIDeNT trial). Health Technol Assess 2015;19:1-164.

16. Loening-Baucke V. Efficacy of biofeedback training in improving faecal incontinence and anorectal physiologic function. Gut 1990;31:13951402.

17. Davis KJ, Kumar D, Poloniecki J. Adjuvant biofeedback following anal sphincter repair: a randomized study. Aliment Pharmacol Ther 2004;20:539-549.

18. Rao SS, Welcher KD, Happel J. Can biofeedback therapy improve ano- rectal function in fecal incontinence? Am J Gastroenterol 1996;91:23602366.

19. Ozturk R, Niazi S, Stessman M, Rao SS. Long-term outcome and objective changes of anorectal function after biofeedback therapy for faecal incontinence. Aliment Pharmacol Ther 2004;20:667-674.

20. Heymen S, Scarlett Y, Jones K, Ringel Y, Drossman D, Whitehead WE. Randomized controlled trial shows biofeedback to be superior to pelvic floor exercises for fecal incontinence. Dis Colon Rectum 2009;52:17301737.

21. Swash M. Electrophysiological investigation of the posterior pelvic floor musculature. The pelvic floor. London: WB Saunders 2002:213-236.

22. Knowles CH. Human studies of anorectal sensory function. Ir J Med Sci 2018;187:1143-1147.

23. Jorge JM, Wexner SD. Etiology and management of fecal incontinence. Dis Colon Rectum 1993;36:77-97.

24. Lewis SJ, Heaton KW. Stool form scale as a useful guide to intestinal transit time. Scand J Gastroenterol 1997;32:920-924.

25. Avery K, Donovan J, Peters TJ, Shaw C, Gotoh M, Abrams P. ICIQ: a brief and robust measure for evaluating the symptoms and impact of urinary incontinence. Neurourol Urodyn 2004;23:322-330.

26. Badia X, Roset M, Montserrat S, Herdman M, Segura A. [The Spanish version of EuroQol: a description and its applications. European quality of life scale.] Med Clin (Barc) 1999;112(suppl 1):79-85.[Spanish]

27. Nockolds CL, Hosker GL, Kiff ES. Compound muscle action potential of the external anal sphincter. Colorectal Dis 2013;15:1289-1294.

28. Markland AD, Jelovsek JE, Whitehead WE, et al. Improving biofeedback for the treatment of fecal incontinence in women: implementation of a standardized multi-site manometric biofeedback protocol. Neurogastroenterol Motil 2017;29:e12906.

29. Norton C, Gibbs A, Kamm MA. Randomized, controlled trial of anal electrical stimulation for fecal incontinence. Dis Colon Rectum 2006;49:190-196.

30. Eléouet M, Siproudhis L, Guillou N, Le Couedic J, Bouguen G, Bretagne JF. Chronic posterior tibial nerve transcutaneous electrical nerve stimulation (TENS) to treat fecal incontinence (FI). Int J Colorectal Dis 2010;25:1127-1132.

31. Pascual-Marqui RD, Michel CM, Lehmann D. Low resolution electromagnetic tomography: a new method for localizing electrical activity in the brain. Int J Psychophysiol 1994;18:49-65.

32. Rothbarth J, Bemelman WA, Meijerink WJ, et al. What is the impact of fecal incontinence on quality of life? Dis Colon Rectum 2001;44:67-71.

33. Findlay JM, Yeung JM, Robinson R, Greaves H, Maxwell-Armstrong C. Peripheral neuromodulation via posterior tibial nerve stimulation a potential treatment for faecal incontinence? Ann R Coll Surg Engl 2010;92:385-390.

34. Healy CF, Brannigan AE, Connolly EM, et al. The effects of low-frequency endo-anal electrical stimulation on faecal incontinence: a prospective study. Int J Colorectal Dis 2006;21:802-806.

35. Boyle DJ, Prosser K, Allison ME, Williams NS, Chan CL. Percutaneous tibial nerve stimulation for the treatment of urge fecal incontinence. Dis Colon Rectum 2010;53:432-437.

36. Byrne CM, Solomon MJ, Young JM, Rex J, Merlino CL. Biofeedback 
for fecal incontinence: short-term outcomes of 513 consecutive patients and predictors of successful treatment. Dis Colon Rectum 2007;50:417427.

37. Amend B, Matzel KE, Abrams P, de Groat WC, Sievert KD. How does neuromodulation work. Neurourol Urodyn 2011;30:762-765.

38. Fowler CJ, Swinn MJ, Goodwin RJ, Oliver S, Craggs M. Studies of the latency of pelvic floor contraction during peripheral nerve evaluation show that the muscle response is reflexly mediated. J Urol 2000;163:881883.
39. Rao SS, Azpiroz F, Diamant N, Enck P, Tougas G, Wald A. Minimum standards of anorectal manometry. Neurogastroenterol Motil 2002;14:553559.

40. Uludag O, Morren GL, Dejong CH, Baeten CG. Effect of sacral neuromodulation on the rectum. Br J Surg 2005;92:1017-1023.

41. Patton V, Wiklendt L, Arkwright JW, Lubowski DZ, Dinning PG. The effect of sacral nerve stimulation on distal colonic motility in patients with faecal incontinence. Br J Surg 2013;100:959-968. 